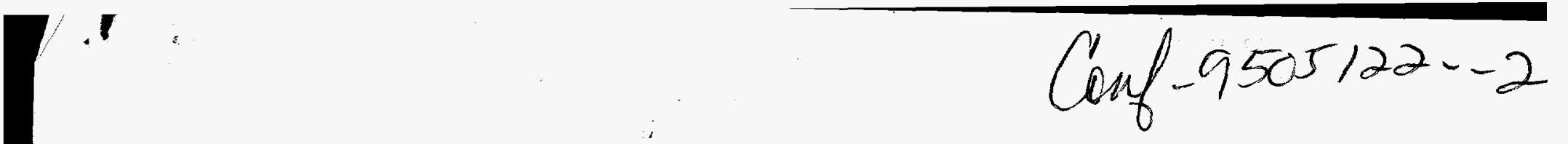

PNL-SA-26451

\title{
IN SITU MEV ION BEAM ANALYSIS OF CERAMIC SURFACES MODIFIED BY 100-400 KEV ION IRRADIATION
}

\author{
W. J. Weber \\ N. $\mathrm{Yu}^{(\mathrm{a})}$ \\ K. E. Sickafus ${ }^{(a)}$ \\ M. Nastasi ${ }^{(a)}$ \\ J. N. Mitchell ${ }^{(a)}$ \\ C. J. Maggiore ${ }^{(a)}$
}

C. R. Evans ${ }^{(a)}$

M. G. Hollander ${ }^{(a)}$

J. R. Tesmer ${ }^{(a)}$

T. E. Levine $e^{(b)}$

J. W. Mayer ${ }^{(c)}$

May 1995

Presented at the

12th International Conference on Ion Beam

Analysis

May 22-26, 1995

Tempe, Arizona

Prepared for

the U.S. Department of Energy

under Contract DE-AC06-76RLO 1830

Pacific Northwest Laboratory

Richland, Washington 99352

(a) Los Alamos National Laboratory, Los Alamos, New Mexico

(b) Cornell University, Ithaca, New York

(c) Arizona State University, Tempe, Arizona

\section{DISCLAIMER}

This report was prepared as an account of work sponsored by an agency of the United States Government. Neither the United States Government nor any agency thereof, nor any of their employees, makes any warranty, express or implied, or assumes any legal liability or responsibility for the accuracy, completeness, or usefulness of any information, apparatus, product, or process disclosed, or represents that its use would not infringe privately owned rights. Reference herein to any specific commercial product, process, or service by trade name, trademark, manufacturer, or otherwise does not necessarily constitute or imply its endorsement, recommendation, or favoring by the United States Government or any agency thereof. The views and opinions of authors expressed herein do not necessarily state or reflect those of the United States Government or any agency thereof.
DISTAIBUTION OF THIS DOCUMENT IS UNLIMTTED

MASTER 


\section{DISCLAIMER}

Portions of this document may be illegible in electronic image products. Images are produced from the best available original document. 


\title{
In situ $\mathrm{MeV}$ ion beam analysis of ceramic surfaces modified by $100-400 \mathrm{keV}$ ion irradiation*
}

Ning Yu ${ }^{\text {a, }}$, Timothy E. Levine ${ }^{b}$, Kurt E. Sickafus ${ }^{\mathbf{a}}$, Michael Nastasi ${ }^{\mathbf{a}}$, Jeremy N. Mitchell,

Carl J. Maggiore ${ }^{a}$, Caleb R. Evans ${ }^{a}$, Mark G. Hollander ${ }^{a}$, Joseph R. Tesmer ${ }^{2}$, William J. Weber ${ }^{c}$, and James W. Mayer ${ }^{d}$

${ }^{a}$ Materials Science and Technology Division, Los Alamos National Laboratory, Los Alamos, NM 87545, USA

bDepartment of Materials Science and Engineering, Cornell University, Ithaca, NY, 14853, USA

'Materials Science Department, Pacific Northwest Laboratory, Richland, WA 99352, USA

${ }^{\mathrm{d} D e p a r t m e n t ~ o f ~ C h e m i c a l, ~ B i o, ~ a n d ~ M a t e r i a l s ~ E n g i n e e r i n g, ~ A r i z o n a ~ S t a t e ~ U n i v e r s i t y, ~ T e m p e, ~ A Z ~}$ 85287 , USA

\begin{abstract}
This paper describes use of the in situ ion beam analysis facility developed at Los Alamos National Laboratory for the study of irradiation effects in ceramic materials. In this facility, an analytical beamline of $3 \mathrm{MV}$ tandem accelerator and an irradiation beamline of $200 \mathrm{kV}$ ion implanter are connected at $60^{\circ}$ to a common target chamber. This facility provides a fast, efficient, and quantitative measurement tool to monitor changes of composition and crystallinity of materials irradiated by $100-400 \mathrm{keV}$ ions through sequential measurement of backscattering events of $\mathrm{MeV}$ ions combined with ion channeling techniques. We will describe the details of the in situ ion beam analysis and ion irradiation and discuss some of the important issues and their solutions associated with the in situ experiment. These issues include (1) the selection of axial ion channeling direction for the measurement of radiation damage; (2) surface charging and charge collection for data acquisition; (3) surface sputtering during ion irradiation; (4) the effects of $\mathrm{MeV}$ analytical beam on the materials; and (5) the sample heating effect on ion beam analysis.
\end{abstract}

*Work sponsored by the U.S. Department of Energy, Office of Basic Energy Sciences, Division of Materials Sciences.

"Corresponding author. Tel. +505665 3459. Fax +505 6653935.

Paper to be submitted to Nucl. Instru. and Meth. B. (1995). 


\section{Introduction}

A facility for the in situ ion beam analysis for research on materials surface modification has been recently developed at the Ion Beam Materials Laboratory (IBML) at Los Alamos National Laboratory (LANL) [1]. The detailed description of ion beam facilities at the IBML has been published elsewhere [2]. In the newly developed in situ facility, a $45^{\circ}$ left beamline (analytical beamline) from a $3 \mathrm{MV}$ tandem accelerator is joined by a second beamline (irradiation beamline) from a $200 \mathrm{kV}$ ion implanter in a surface modification chamber (in situ chamber), as shown in Fig. 1. The analytical beamline is used for ion beam analysis of the materials, in particular for Rutherford backscattering spectrometry (RBS) measurement. The irradiation beamline is for ion irradiation of the materials. The angle between two beamlines on their co-plane is $60^{\circ}$. This facility provide a fast, efficient, and quantitative tool to monitor changes of stoichiometry and crystallinity of materials, irradiated by a $100-400 \mathrm{keV}$ ion beam, using sequential RBS measurements of a MeV He ion beam. We used the in situ facility to study the kinetics of ion-beam-induced densification of sol-gel zirconia $\left(\mathrm{ZrO}_{2}\right)$ thin films [1,3] and radiation damage in several ceramic single crystals, e.g., $\mathrm{MgAl}_{2} \mathrm{O}_{4}[1,4], \mathrm{MgTiO}_{3}[5]$, and $6 \mathrm{H}-\mathrm{SiC}[6]$ at different temperatures. In this paper, we will describe the basic aspects of in situ experiment in detail. Some of important issues associated with the in situ experiment will be discussed. These issues include (1) the selection of axial ion channeling direction for the measurement of radiation damage; (2) surface charging and charge collection for data acquisition; (3) surface sputtering during ion irradiation; (4) the effects of $\mathrm{MeV}$ analytical beam on the materials; and (5) the sample heating effect on ion beam analysis.

\section{Sample installation}

The samples used for ion irradiation study had a typical dimension of 1-3 $\mathrm{cm}$ width and $0.5 \mathrm{~mm}$ thickness. The samples were glued to a sample holder, made of pure copper, with silver paint to improve thermal conduction and reduce sample surface charging. The sample holder, with a dimension of $3.5 \mathrm{~cm}$ diameter and $2.5 \mathrm{~mm}$ thickness, was mechanically clamped onto a heating stage, which was seated on a multi-axis goniometer (Fig. 1). A disk-shaped resistive heater, made of hexagonal boron nitride and graphite composite, was permanently installed inside the heating unit. The heater allowed fast heating of the small sample holder and the sample up to $500^{\circ} \mathrm{C}$ 
within 30 minutes. The sample could also be cooled to $-100^{\circ} \mathrm{C}$ using liquid nitrogen conduction cooling. The edge of the sample holder was connected with a liquid nitrogen reservoir through a $3.5 \mathrm{~mm}$ diameter, $18 \mathrm{~cm}$ long pure copper braid. The reservoir, with a volume capacity of $64 \mathrm{~cm}^{3}$, was extended outside the chamber through an isolation vacuum feedthrough. Less than one hour was required to cool the sample stage from room temperature to $-100^{\circ} \mathrm{C}$. The temperature on the sample was monitored by a thermocouple attached to the edge of the sample holder, opposite to the cooling braid. The typical power load of an ion beam on the sample was $0.2 \mathrm{~W}$ or less during ion irradiation and ion beam analysis $(400 \mathrm{kV}, 0.5 \mu \mathrm{A}$ and $2 \mathrm{MV}, 100 \mathrm{nA})$. The temperature rise on the sample due to the beam heating was less than $5^{\circ} \mathrm{C}$. Typical vacuum in the chamber was $2 \times 10^{-7}$ torr.

\section{Ion beam analysis and ion irradiation}

For radiation effects study, RBS in conjunction with ion channeling techniques was employed to detect radiation damage in single crystal samples. The sample, mounted on the sample stage, was first aligned with one of its crystallographic axes along the $2 \mathrm{MeV} \mathrm{He}^{+}$ion beam from the tandem accelerator. The selection of axial ion channeling directions for radiation detection will be discussed in the next section. The size of the analytical beam was $2 \mathrm{~mm}$ diameter on the sample surface. Two gold-silicon surface barrier detectors (Fig. 1) were installed in the target chamber to detect backscattered $\mathrm{He}$ particles at scattering angles of $165^{\circ}$ and $120^{\circ}$, respectively. The channeling alignment was performed by both sample tilt and rotation motion through a computer-controlled goniometer. The accuracy of the angular motion was better than $0.1^{\circ}$. For alignment, the rotation axis of the sample stage was co-planar with the $\mathrm{He}$ ion beam to avoid the motion of the analytical beam spot on the sample surface. The second step, after alignment, was to bring the sample to a temperature at which the ion irradiation was to be conducted. It was confirmed that the heating or cooling caused no measurable changes in the sample orientation. Then a channeling spectrum was taken on the sample prior to irradiation. The sample was irradiated to an incremental dose with the $100-400 \mathrm{keV}$ ion beam from the ion implanter and subsequently analyzed with the $2 \mathrm{MeV}$ He ion beam. The irradiation beam spot on the sample was $6 \mathrm{~mm}$ in diameter. The analytical beam was co-centered with the irradiation beam to ensure the detection of the radiation-damaged area on the sample. During ion irradiation, a 
shutter blocked the detectors to prevent backscattered heavy particles from hitting the detectors. The irradiation experiment was carried on until the lattice disorder in the irradiated sample reached a certain saturation level such as amorphization. For samples with a large enough size, it was convenient to restart a similar irradiation experiment at a different temperature without breaking the vacuum. The sample could be translated vertically up to $\pm 2 \mathrm{~cm}$ through manual control (see Fig. 1) to set an unirradiated area exposure to the ion beams. No further realignment was required since the vertical motion introduced no measurable changes in the sample orientation.

For the ion beam densification experiment, the samples with sol-gel zirconia films coated on $\mathrm{Si}$ wafers were oriented directly at $60^{\circ}$ with respect to the analytical beam and with normal incident to the irradiation beam [3].

\section{Selection of axial channeling directions}

To maintain equivalent experimental conditions throughout the radiation experiment, we always avoided changing the sample orientation once it was aligned. A key step was to choose a fixed axial channeling orientation of the sample for the detection of radiation damage, which compromised the incident geometry for both analysis and irradiation. Criteria for selecting an axial ion channeling direction included (1) minimizing the incident angle for the irradiation beam and (2) achieving the backscattering yield as low as possible. Small incident angle is preferable to glancing incident angle for the irradiation in order to minimize surface sputtering of the irradiated sample, which will be discussed in Section 6. Physically, there was always a $60^{\circ}$ angle between two beamlines. We intended not to choose the major axial channeling direction close to the sample normal to avoid a $60^{\circ}$ glancing incident for the irradiation. A specific channeling direction, with a relatively low backscattering yield, had to be selected among many crystallographic directions that were away from the sample normal. The channeling direction with a low minimum yield provided a high sensitivity to detect radiation damage in the single crystal sample. In reality, the optimum channeling axis was chosen based upon the structure and the orientation of the single-crystalline specimen. For cubic $\mathrm{MgAl}_{2} \mathrm{O}_{4}$ spinel with $\left.<100\right\rangle$ orientation, the $\langle 110\rangle$ axial channeling direction was chosen. The minimum yield along the $<110>$ axis $(3 \%)$ was even a little bit lower than that along the $\langle 100\rangle$ axis $(4 \%)$. The use of $\langle 110\rangle$ axis for ion channeling 
measurement maintained $45^{\circ}$ and $15^{\circ}$ incident angles of the analytical beam and the irradiation beam, respectively. For hexagonal structures such as $6 \mathrm{H}-\mathrm{SiC}$ and $\mathrm{MgTiO}_{3}$, it is known that along a c-cut direction, i.e., $<0001>$ axis, the lowest minimum yield is achieved $(2 \%)$. On these materials with the c-cut orientation, however, we had to choose an axial channeling direction among crystallographic axes with relatively high Miller indices. For c-cut $6 \mathrm{H}-\mathrm{SiC}$ crystal, the $<1012>$ axis was selected, which has a $35.3^{\circ}$ angle with respect to the $\mathrm{c}$-axis. For c-cut $\mathrm{MgTiO}_{3}$ crystal, the $<1014>$ axis was used (a $35^{\circ}$ angle to the c-axis). The minimum yields along these chosen directions were higher ( $7 \%$ ) compared to the c-axis, as shown in Fig. 2, but they were still relatively lower compared to other adjacent channeling directions.

\section{Surface charging and charge collection}

The ceramic oxides we studied, such as $\mathrm{MgAl}_{2} \mathrm{O}_{4}$ and $\mathrm{MgTiO}_{3}$, were good electrical insulators. Sample-surface charging due to ion charge accumulation by analytical and irradiation beams always existed and caused some problems. The surface charging interfered with charge collection to determine the delivered dose from analytical and irradiation beams. The constant charging and subsequent arcing could also severely distort the backscattering spectrum due to variation of the retarding potential (a few $\mathrm{keV}$ ) on the sample surface. We developed several solutions to these problems. A four-corner Faraday-cup apparatus, used mostly for implantation processes in the semiconductor industry, was installed in the irradiation beamline near the in situ chamber (see Fig. 1). The irradiation beam was uniformly rastered across the entire area of the four-corner-cup during irradiation and only a small portion of the beam through a central aperture ( $6 \mathrm{~mm}$ diameter) was delivered onto the sample surface. The irradiation dose was determined by the charge collection from the four-corner-cup connected with a dose processor. The sample stage, which was isolated from electrical ground, was always biased at $300 \mathrm{~V}$ and connected with a current integrator for charge collection of the analytical beam during the in situ experiment. The bias was necessary to suppress secondary electron emission. Extra silver paint decorated along the edge of small samples $(4 \mathrm{~mm}$ ) could effectively reduce surface charging. The surface charging problems could be effectively solved if the insulating sample surface was coated with a thin layer (1-3 nm thick) of conducting material, such as a metallic film or an amorphous carbon film. The selection of heavy metals or carbon for surface coating could avoid the interference of the RBS 
spectrum from the substrate with that from the thin film. Noble metals such as platinum and gold do not wet oxide surfaces, and therefore the thin coating does not form a continuos layer. We noted that iridium readily wets oxide surfaces, forming a conductive iridium oxide layer. Iridium coating effectively minimized charging effects on oxide ceramics.

\section{Surface sputtering issues}

The $100-400 \mathrm{keV}$ irradiation beam not only introduced lattice disorder in the irradiated surface region (100-200 nm thick), but also caused surface sputtering (surface erosion). The surface sputtering became severe for heavy ion species such as $\mathrm{Kr}$ and $\mathrm{Xe}$ with a glancing incident geometry. The metallic coating on the oxide surface could be more readily sputtered off than the oxide surface due to the lower surface binding energy of metals. Fig. 3 shows channeling spectra of $2 \mathrm{MeV} \mathrm{He}$ ions from a (100) $\mathrm{MgAl}_{2} \mathrm{O}_{4}$ spinel sample, coated with an $1 \mathrm{~nm}$ gold thin film, before and after $370 \mathrm{keV} \mathrm{Xe}{ }^{2+}$ ion irradiation at $-50^{\circ} \mathrm{C}$ to a dose of $2 \times 10^{15} \mathrm{Xe} / \mathrm{cm}^{2}$. The Xe ions were incident at $15^{\circ}$ with respect to the sample normal. It is obvious, from the gold signal in the spectra, that the gold coating was almost completely removed by $2 \times 10^{15} \mathrm{Xe} / \mathrm{cm}^{2}$, long before the spinel surface transformed into an amorphous phase at $2 \times 10^{16} \mathrm{Xe} / \mathrm{cm}^{2}$ (data not shown). The removal of metallic film coating by sputtering could cause surface charging problems for analysis. However, most often surface charging became less severe after the sample had experienced a certain amount of irradiation dose. This was due to ion-bombardment induced carbon deposition from the vacuum chamber. The carbon deposition caused by the analytical beam will be discussed in the next section. The surface sputtering did not interfere with the kinetic study of radiation damage in the depth well below the surface (100-200 nm) since sputtering at most removed a 10 $\mathrm{nm}$ surface layer.

\section{The effects of analytical beam on the materials}

Ion irradiation and ion beam analysis were performed on the same sample area throughout each in situ experiment. To achieve good statistics for the backscattering spectrum and a good kinetic curve, each spectrum was taken with a fixed charge of $10-20 \mu \mathrm{C}$ and twenty spectra were routinely collected on the same sample spot. The total charge of $\mathrm{He}^{+}$ions deposited in a sample area of $2 \mathrm{~mm}$ diameter was $200-400 \mu \mathrm{C}$, corresponding to doses of $(4-8) \times 10^{16} \mathrm{He} / \mathrm{cm}^{2}$. These $\mathrm{He}$ 
ions stopped in the target materials at a depth greater than $4 \mu \mathrm{m}$, which was beyond the regions of interest (100-200 nm) in our radiation damage studies. Furthermore, most of ceramics we studied were relatively radiation resistant in comparison to semiconductor materials such as $\mathrm{Si}$ and $\mathrm{Ge}$. Therefore, a high dose irradiation with a $\mathrm{MeV}$ He ion beam introduced no observable radiation damage and chemical effects in the near surface region. Fig. 4 shows channeling spectra of $2 \mathrm{MeV}$ He ions taken from a $6 \mathrm{H}-\mathrm{SiC}$ crystal along the $<0001>$ axis, irradiated with the same analytical beam to 40 and $400 \mu \mathrm{C}$. No difference in the dechanneling yield is observed over the entire displayed region $(1 \mu \mathrm{m})$ except an increase in the area under the carbon surface peak. The increase in the carbon surface peak cannot be due to surface damage induced by the He ion beam since no corresponding increase in the silicon surface peak is observed in Fig. 4. Therefore, the increase in the carbon surface peak was caused only by ion-beam-induced carbon deposition from the vacuum.

For materials exhibiting sensitivity to ion irradiation, e.g., sol-gel zirconia films, ion bombardment with an analytical beam could affect materials being studied. The sol-gel thin films contained hydrogen, carbon, and excess oxygen. It was shown that even at $-100^{\circ} \mathrm{C}$, the irradiation of $280 \mathrm{keV}$ noble gas ions, such as $\mathrm{Ar}$ and $\mathrm{Xe}$ ions, produced dramatic densification in the films. The densification was characterized by the loss of gaseous hydrogen, carbon, and oxygen-based chemical groups $[3,7]$. Fig. 5 shows RBS spectra from a $80 \mathrm{~nm}$ zirconia sol-gel film coated on (100) silicon wafer bombarded with $3.55 \mathrm{MeV} \mathrm{He}^{2+}$ ions to 20 and $330 \mu \mathrm{C}$. A small increase $(10 \%)$ in the height of zirconium signal, as the collected charge accumulated from 20 to $330 \mu \mathrm{C}$, indicates some densification induced by the analytical beam alone. We noted that most of the densification took place during the first $60 \mu \mathrm{C}$ of data acquisition and that the $3.55 \mathrm{MeV}$ He ion beam induced the release, for the most part, hydrogen species. The densification is much less than the maximum densification achieved by $280 \mathrm{keV}$ noble gas ions with a $50 \%$ increase in the zirconium RBS signal height.

\section{Sample heating effect on ion beam analysis}

The capability of performing the in situ ion irradiation experiment at high temperatures is important for radiation damage and ion beam induced epitaxial growth study. However, the detection of backscattered particles is limited by the unwanted heating on the surface barrier 
detectors from the heated sample stage. The detectors have excessive leakage current once their temperatures reach above $50^{\circ} \mathrm{C}$. We tested the sample heating effect on the detector performance. As the sample temperature was raised from room temperature through $60^{\circ} \mathrm{C}$ to $100^{\circ} \mathrm{C}$ (with heating power of $30 \mathrm{~W}$ ), no significant change in the channeling spectrum was observed, as shown in Fig. 6 for the $6 \mathrm{H}-\mathrm{SiC}$ crystal. The small increase in dechanneling yield in the spectrum was due to an increase in lattice thermal vibrations. The energy resolution of the detector gradually degraded with the increase in the sample temperature from 120 to $300^{\circ} \mathrm{C}$. The spectrum became unusable as the sample temperature reached $300^{\circ} \mathrm{C}$ (with heating power of $130 \mathrm{~W}$ ) due to leakage current in the detector. Since there was no direct thermal contact between the sample stage and the detector, the temperature rise in the detector was due solely to the thermal radiation heating effect. The heating took much longer to reach thermal equilibrium on the detector when the sample temperatures were below $300^{\circ} \mathrm{C}$. By blocking the detector with the shutter when not taking data, the detector heating was partially reduced. We expect that the heating effect on the backscattering detection can be effectively overcome by shielding the detector and cooling it and its surroundings. The development of detector cooling capability is in progress.

\section{Conclusions}

The in situ ion beam facility at the IBML has been developed for the purpose of measuring the composition and crystallinity of materials irradiated with a $100-400 \mathrm{keV}$ ion beam in a fast, efficient, controlled, and quantitative manner. It plays a vital role in radiation damage studies of ceramics being conducted at LANL. Radiation effects in several ceramic materials have been studied using this facility. Many useful experimental techniques, dealing with in situ ion beam analysis and ion irradiation, have been developed for radiation damage studies. Axial channeling directions with acceptably low minimum yields have to be chosen for the detection of radiation damage in single crystals. The selected channeling directions also need to satisfy the requirement of a small incident angle for irradiation in order to minimize surface sputtering. The surface charging on insulating materials can be minimized with proper coating of thin conducting materials. For many radiation resistant ceramics, high doses $\left(8 \times 10^{16} \mathrm{He} / \mathrm{cm}^{2}\right)$ of $\mathrm{MeV}$ analytical 
He ion beams show no observable radiation damage or chemical effects in the near surface region, where significant lattice disorder is produced only by the $100-400 \mathrm{keV}$ irradiating beams. Detector heating due to thermal radiation from the heated sample stage can be overcome by properly shielding and ultimately cooling the detector. 


\section{References}

[1] N. Yu, M. Nastasi, T.E. Levine, J.R. Tesmer, M.G. Hollander, C.R. Evans, and C.J. Maggiore, Nucl. Instru. Meth. B, (1995), in press.

[2] J.R. Tesmer, D.M. Parkin, and C.J. Maggiore, Mater. Res. Soc. Bull. XII (1987) 101.

[3] T.E. Levine, N. Yu, P. Kodali, K.C. Walter, M. Nastasi, J.R. Tesmer, C.J. Maggiore, and J.W. Mayer, submitted to Nucl. Instru. Meth. B, (1995).

[4] N. Yu, M. Nastasi, M.G. Hollander, C.R. Evans, C.J. Maggiore, K.E. Sickafus, J.R. Tesmer, Mat. Res. Soc. Symp. Proc. 316 (1994) 69.

[5] J.N. Mitchell, N. Yu, K.E. Sickafus, and M. Nastasi, (1995), to be published.

[6] W.J. Weber, N. Yu, et al., (1995), to be published.

[7] T.E. Levine, P. Revesz, E.P. Giannelis, and J.W. Mayer, J. Vac. Sci. Technol. B 12 (1994) 986. 


\section{Figure captions}

Figure 1 Schematic drawing of the sample stage installed within the in situ ion beam chamber in connection with both analytical and irradiation beamlines.

Figure 2 Aligned backscattering spectra from a c-cut $\mathrm{MgTiO}_{3}$ single crystal obtained along the $<0001>$ and $<1014>$ channeling axes, along with the random spectrum.

Figure 3 Aligned backscattering spectra obtained from a (100) $\mathrm{MgAl}_{2} \mathrm{O}_{4}$ single crystal, coated with an $1 \mathrm{~nm} \mathrm{Au}$ film, along the $\langle 110\rangle$ channeling direction, before and after the irradiation of $370 \mathrm{keV} \mathrm{Xe}$ ions at $-50^{\circ} \mathrm{C}$ to $2 \times 10^{15} \mathrm{Xe} / \mathrm{cm}^{2}$.

Figure 4 Aligned backscattering spectra from a c-cut $6 \mathrm{H}-\mathrm{SiC}$ single crystal along the $<0001>$ channeling direction, obtained after bombarded with a $2 \mathrm{MeV}$ analytical $\mathrm{He}^{+}$ion beam to 40 and $400 \mu \mathrm{C}$.

Figure 5 Backscattering spectra from a sol-gel zirconia thin film coated on (100) Si wafer, subject to the bombardment of a $3.55 \mathrm{MeV}$ analytical $\mathrm{He}^{2+}$ ion beam to 20 and $330 \mu \mathrm{C}$.

Figure 6 Aligned backscattering spectra from a c-cut $6 \mathrm{H}-\mathrm{SiC}$ single crystal along the $<1012>$ channeling direction, obtained when the sample temperatures were 60 and $100^{\circ} \mathrm{C}$. 


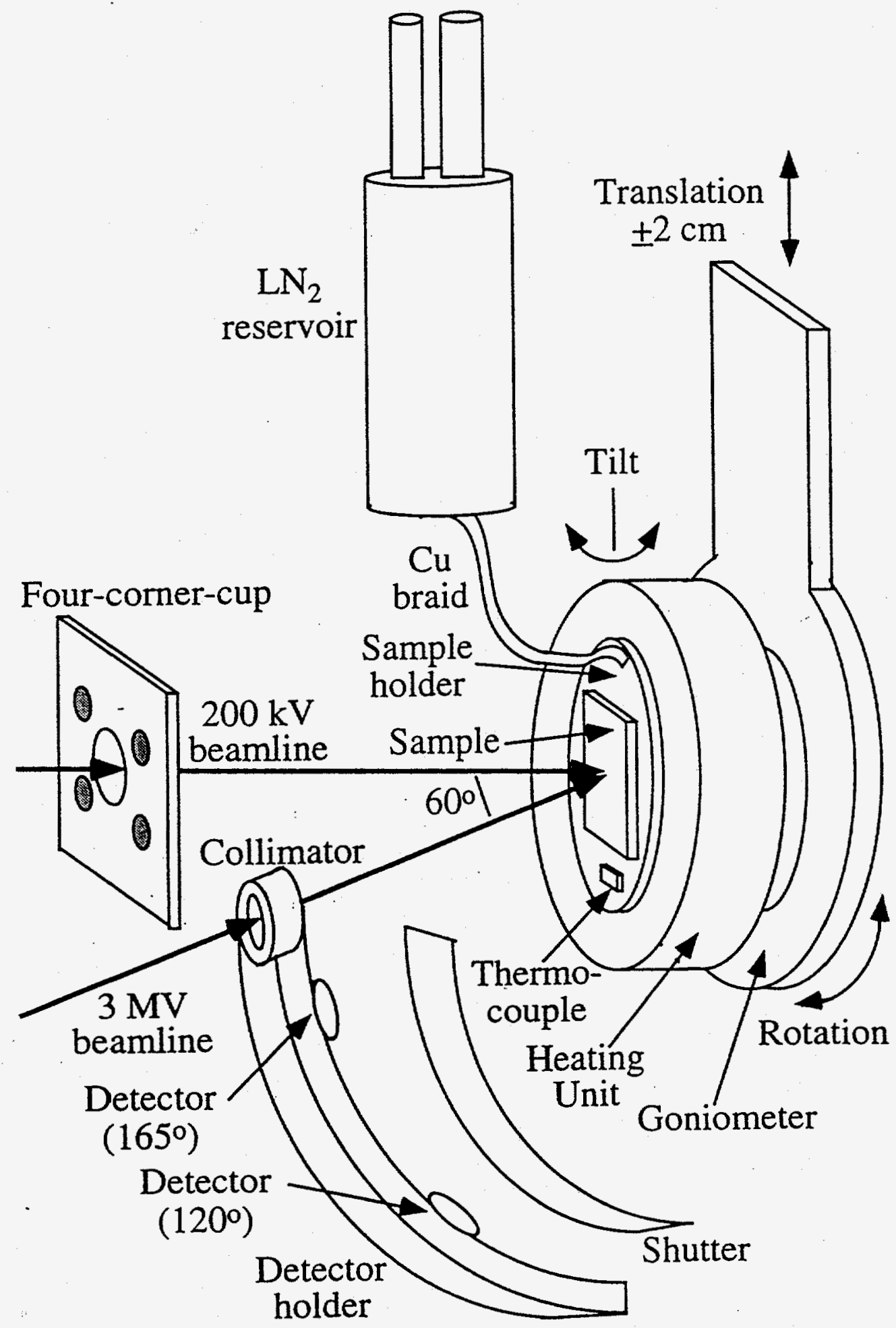

Fig. I 
$\stackrel{N}{i}$

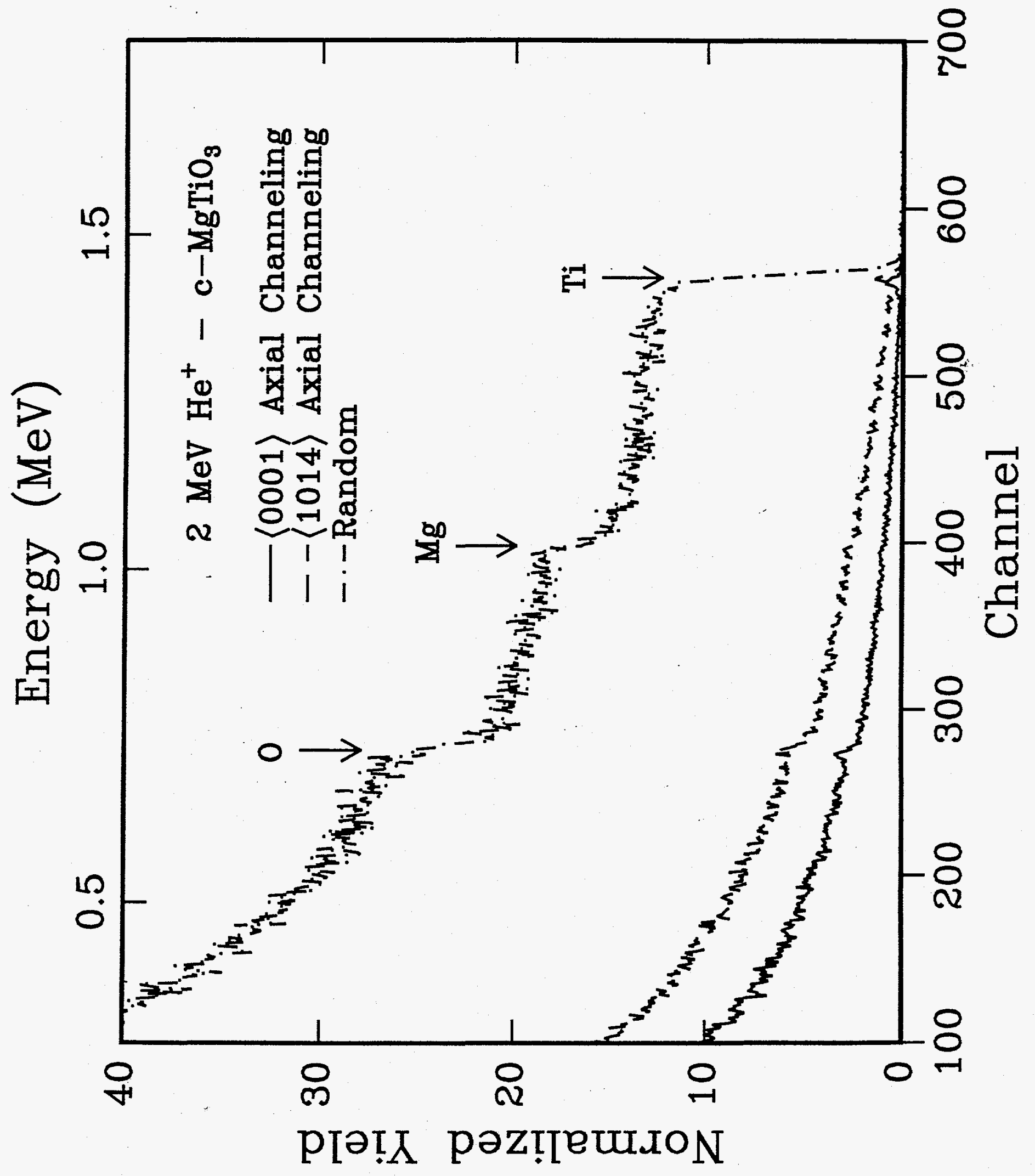


$m$

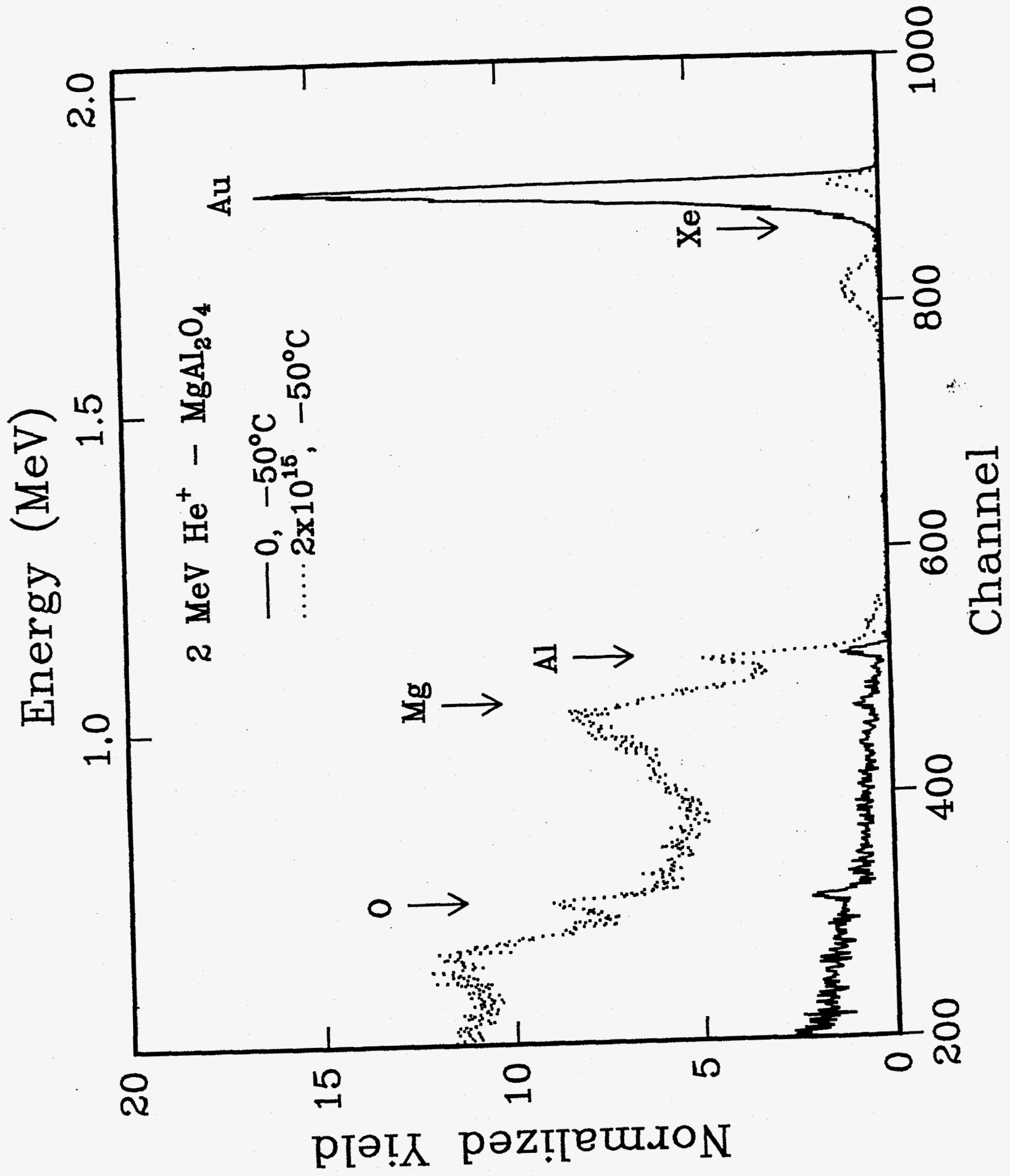




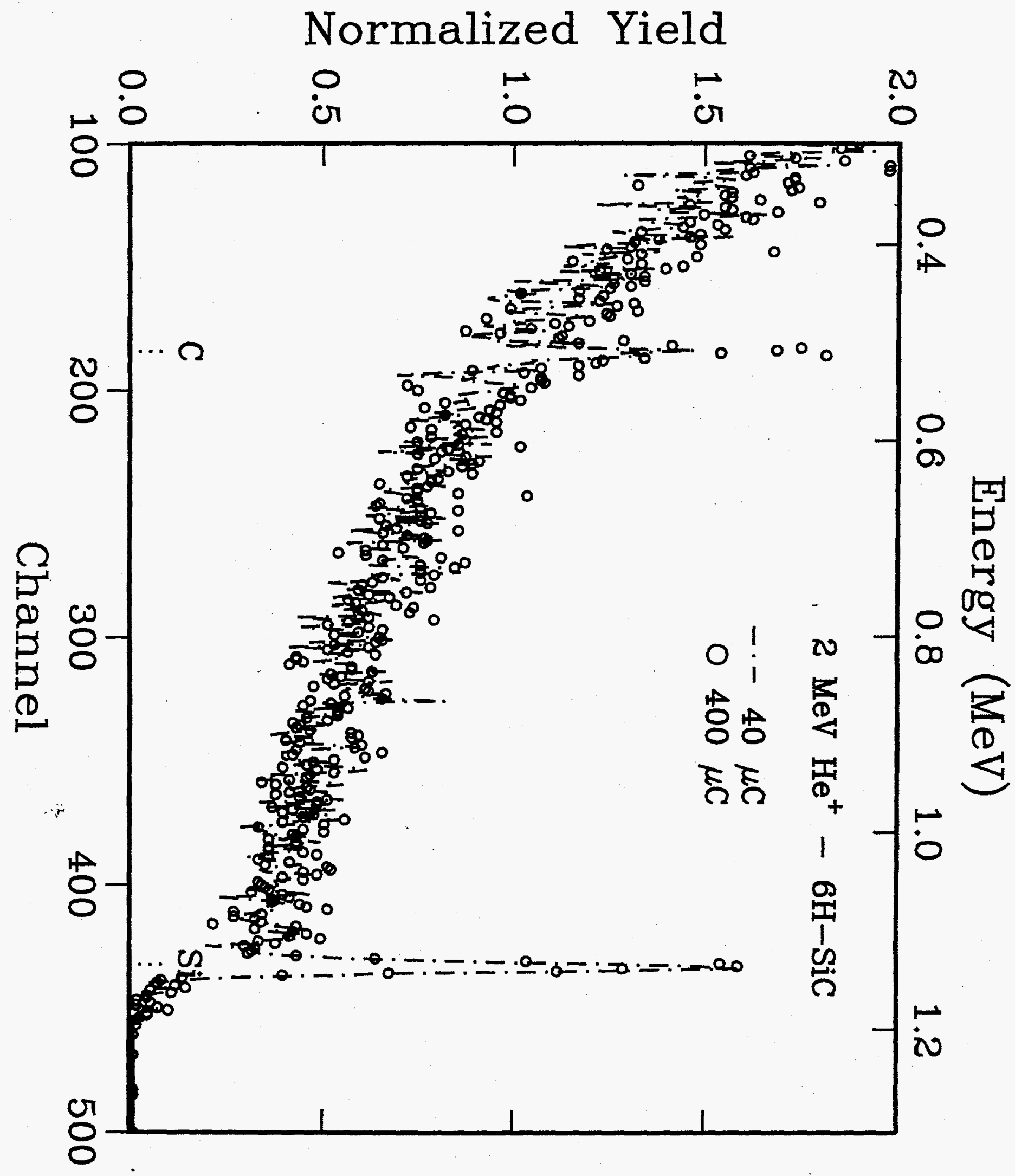

$\frac{\pi}{6}$ 


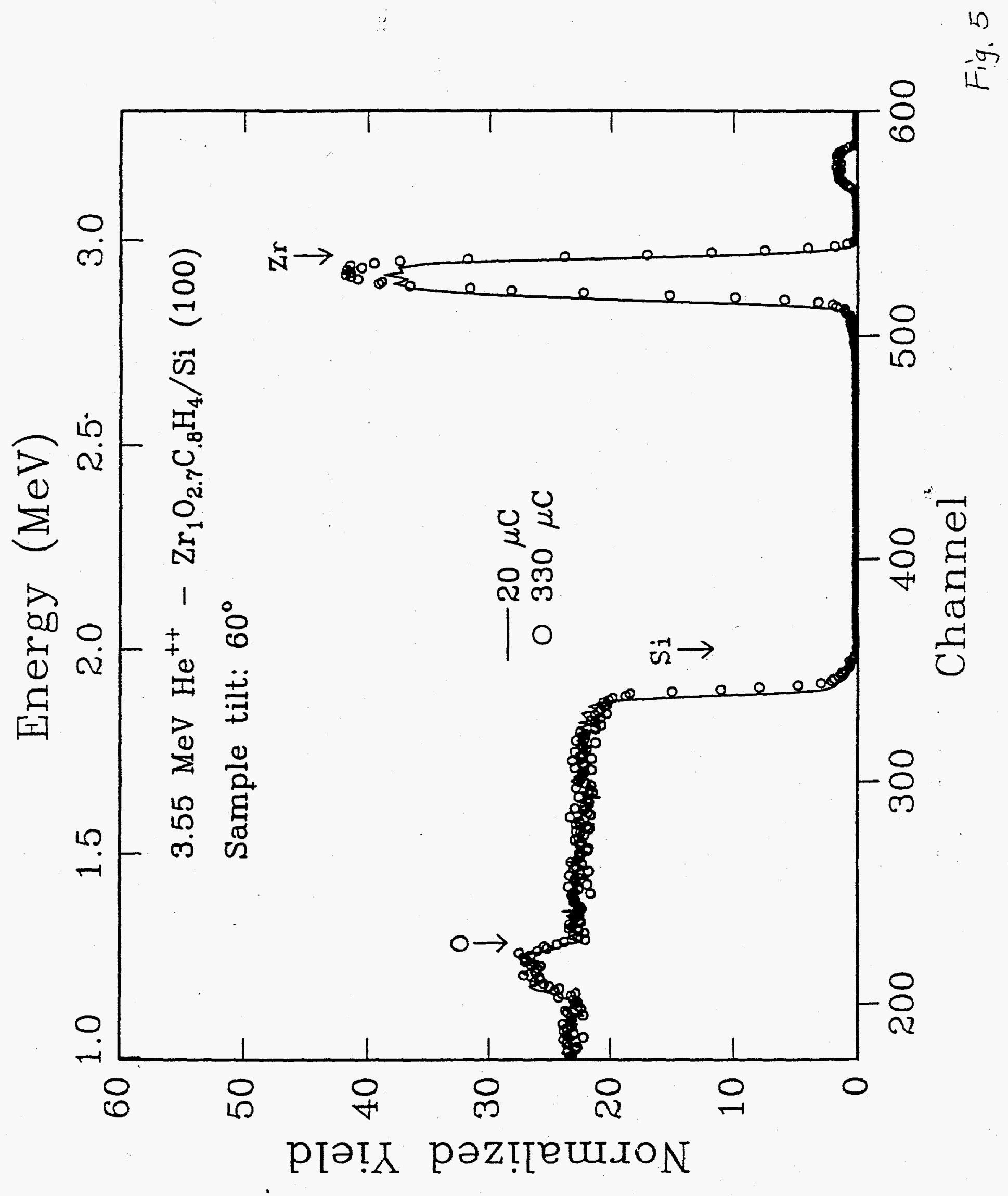




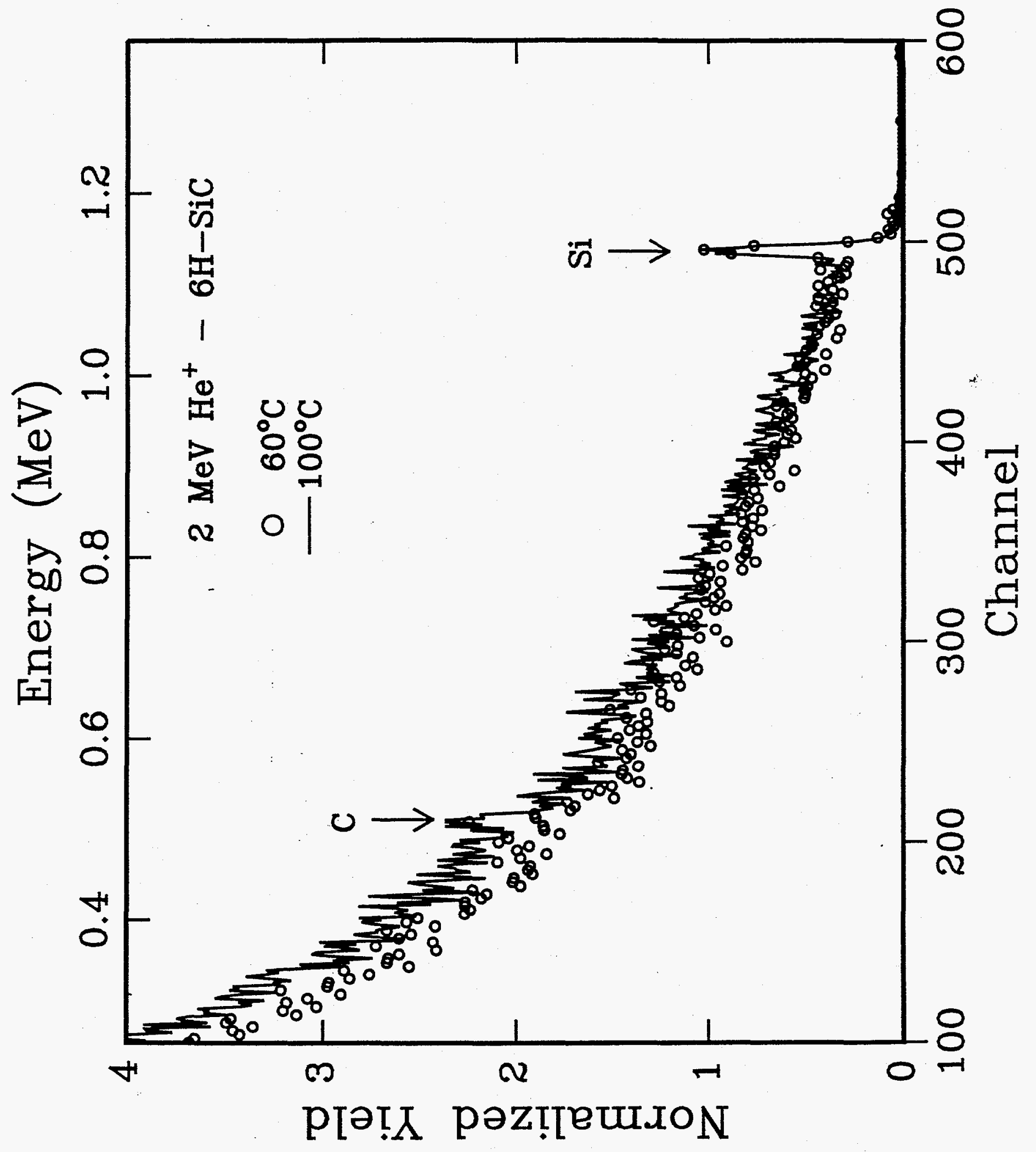

